\title{
Kanzler und Minister: mehr als nur ein Lexikon
}

Kempf, Udo und Hans-Georg Merz (Hrsg.): Kanzler und Minister 1998-2005. Biographisches Lexikon der deutschen Bundesregierungen, VS Verlag für Sozialwissenschaften, Wiesbaden 2008, 396 Seiten, $€ 39,90$.

Erfreulicherweise hat das in dieser Zeitschrift bereits besprochene „Biographische Lexikon der deutschen Bundesregierungen “ für den Zeitraum 1949 bis $1998^{1}$ schon jetzt einen „Fortsetzungsband“ erhalten. Auf fast 400 Seiten werden die Kabinettsmitglieder der sieben Jahre lang von Bundeskanzler Gerhard Schröder (SPD) angeführten „rot-grünen Koalition“ vorgestellt. Mithin handelt es sich um nur 26 Biographien, deren alphabetische Anordnung es rechtfertigt, von einem „Lexikon“ zu sprechen. Bei einer anderen als alphabetischen Anordnung hätte ein gleiches Werk auch den Titel „Lebensbilder“ verdient, weil die Artikel sehr ausführlich sind und eher gut lesbaren biographischen Skizzen in feuilletonistischer Qualität entsprechen als dem Biogramm eines üblichen Nachschlagewerkes. Auch die umfangreiche Einleitung von 124 Seiten, die damit fast ein Drittel des gesamten Bandes ausmacht, spricht gegen ein Lexikon. Aber gerade die Einleitung ist es, die den besonderen Reiz des hier anzuzeigenden Werkes ausmacht, denn sie besteht: (1) aus einer quantitativen Strukturanalyse der Mitglieder der Regierungen Schröder; (2) folgt ein Überblick über „rotgrünes" Regieren im parlamentarischen System und eine Analyse des Regierungshandelns Schröders mit seinen Expertengremien; (3) werden die Minister im Spiegel von Meinungsumfragen einer genauen Betrachtung unterzogen. Vergleiche mit den Regierungsstilen deutscher Vorgänger-Regierungen und anderer europäischer Staaten (zum Beispiel Großbritannien, Italien oder USA) fehlen nicht. Mit anderen Worten: In geradezu vorbildlicher Weise werden die dargebotenen Biographien bereits in der Einleitung systematisch ausgewertet. So entsteht der berechtigte Eindruck, dass das Buch von Kempf und Merz ein Handbuch zur inzwischen Geschichte gewordenen „Schröder-Administration“ und ihrer Regierungspolitik ist, die vielleicht eine Zäsur bildete, aber wohl nicht - wie im Falle Konrad Adenauers - zu einer „Ära Schröder" avancieren wird, weswegen hier richtigerweise vom „System Schröder" geschrieben wurde.

Leider ist es nicht möglich, die Besonderheiten dieses „Systems“ hier aufzuführen; so muss es bei der Empfehlung bleiben, unbedingt in die faktenreiche und gut geschriebene Einleitung hineinzuschauen. Auch die 26 Biographien können nicht einzeln vorgetragen werden. Grundsätzlich fällt auf, dass bei den Ministern, die vorzeitig von ihrem Amt zurücktraten, die exakten Entlassungsdaten zumeist leider fehlen. Auch die chronologische Nennung der wichtigsten Lebensdaten am Anfang eines jeden Lexikonartikels führt nur beim Geburtsdatum den Tag, den Monat und das Jahr auf. Bei der Abfassung der einzelnen Biographien haben sich alle Autoren sinnvollerweise auf die Tätigkeiten der Minister konzentriert und nicht selten ihr besonderes Verhältnis zu Bundeskanzler Schröder ausgelotet. Spannungsgefüge am Kabinettstisch lassen sich somit nachvollziehen.

Der Leser erfährt, warum sich abzeichnete, dass Kurt Bodewig 2002 nicht wieder in sein Ministeramt berufen würde (S. 144); im Artikel über die einstige „Weltverbesserin“ (S. 146) Edelgard Bulmahn wird die Entwicklung der Hochschulreform zwischen „Pisa“ und

1 Vgl. Ferdinand Müller-Rommel, Bedeutendes Kompendium zur bundesdeutschen Elitenforschung, in: ZParl, 32. Jg. (2001), H. 4, S. $888-889$. 
„Bologna“ nachgezeichnet; es wird aufgezeigt, warum Wolfgang Clement „in der historischen Bewertung der deutschen Wirtschaftsminister schwerlich einen Spitzenplatz einnehmen“ (S. 158 f.) wird. Es ist nachzulesen, dass Herta Däubler-Gmelin in „nicht wenigen innerparteilichen Kontroversen polarisierte“ (S. 162) und selbstverständlich auch außerhalb der Partei (S. 170: „Hitler-Bush-Vergleich“) schadete. Über Hans Eichel heißt es, dass er ungeachtet vieler Anfeindungen „bis zur Ablösung des Kabinetts Schröders im Amt ausharrte“, sei „seiner Hartnäckigkeit, seinem Pflichtbewusstsein und seiner - arg strapazierten Loyalität zu Kanzler und Partei zuzuschreiben“ (S. 186). Gern liest man auch den Beitrag über Joschka Fischer und seinen Wandel vom „Straßenkämpfer“ (S. 195) zum Außenminister, der „in einer außergewöhnlichen innerparteilichen Kraftanstrengung seine eigene Partei an die realpolitischen Notwendigkeiten heran“ geführt hatte und „wesentlich zur Stabilisierung des deutschen Regierungssystems“ beitrug (S. 209). Selbst diejenigen, die es vielleicht schon gewusst haben, werden daran erinnert, dass der Rücktritt des „Paradiesvogels“ (S. 220) Bodo Hombach im Zusammenhang mit Oskar Lafontaines Rücktritt als Finanzminister stehen „dürfte“ (S. 219). Der Beitrag über die „grüne Allzweckwaffe“ (S. 224) Renate Elly Künast ist ein schöner Beleg dafür, mit welch großer Sorgfalt biographische Details zusammengetragen und anschaulich vorgetragen werden. Und weil die Biographien die Ministertätigkeit im Blick haben, vermisst der Leser im Beitrag über Ursula („Ulla“) Schmidt „geb. Radermacher" (offensichtlich die einzige Frau im Kabinett, die durch Heirat ihren Mädchennamen abgelegt hatte) nicht wirklich den Hinweis, womit sie als Studentin ihren Lebensunterhalt verdient hatte. Selbstverständlich bekommt der „Basta-Kanzler“ den umfangreichsten Artikel. Der Mitherausgeber Udo Kempfkennt und beherrscht die Literatur über Gerhard Schröder und zeichnet ein gelungenes Bild über seine Kanzlerschaft. Von ihr werden „Riester-Rente“ und „Agenda 2010“ (also der Umbau des Sozialstaates) lange in Erinnerung bleiben, genauso wie jenes Faktum, dass ausgerechnet unter Rot-grün die Bundeswehr in einen Krieg geschickt wurde (und nicht „zog“, wie Kempf, S. 338, schreibt).

Solche Wertungen und Bewertungen machen einmal mehr deutlich, dass auch wenn möglicherweise manche Biografien von Wissenschaftlern verfasst wurden, die der Partei des von ihnen behandelten Ministers nahestehen oder sogar angehören, diese sich verpflichtet fühlten, objektiv zu bleiben und auch gelegentliche Schattenseiten nicht zu verschweigen. So kann am Schluss zweierlei Lob stehen: Ein ehrliches Buch! Und: Mehr als nur ein Lexikon!

Michael F. Feldkamp

\section{Kanzler und ihr Verhältnis zur Öffentlichkeit: wenig überzeugend bearbeitet}

\section{Rosumek, Lars: Die Kanzler und die Medien. Acht Porträts von Adenauer bis Merkel, Campus- Verlag, Frankfurt am Main 2007, 325 Seiten, $€ 29,90$.}

Bis in die Gegenwart reichende Längsschnittanalysen haben einen ganz besonderen Charme: Sie schützen davor, aktuelle Entwicklungen für einmalig zu halten, kontextualisieren sie und können im besten Fall helfen, ihre Ursachen besser zu verstehen. Im Zusammenhang mit den Veränderungen politischer Kommunikation sind in den letzten Jahren eine ganze Reihe solcher Studien publiziert worden. Sie haben sich zum Beispiel mit den 